\title{
SERANGAN SERANGGA PERUSAK PADA CONTOH KAYU DI GUDANG PUSAT PENELITIAN DAN PENGEMBANGAN HASIL HUTAN DAN SOSIAL EKONOMI KEHUTANAN BOGOR
}

\section{(Attack by Deteriorating Insects on Wood Samples in Storeroom of Forest Products and Forestry Socio-economics Research \& Development Centre, Bogor)}

\author{
Oleh/By \\ Paimin Sukartana
}

Summary

Since establishment in around 1920, Forest Products and Forestry Socio-economics Research and Development Centre (FPFSRDC) Bogor, Indonesia continuosly collects various wood samples from throughout the country's forest for experimental purposes. Some wood specimens were kept in xylarium as xylotheca, and some others, the rest of experimental samples, were kept in storeroom.

An observation was conducted to evaluate deterioration of the wood samples kept in storeroom caused by dry-wood termites, powder-post beetles and pin-hole borers. Of the 464 pieces of wood samples representing 84 wood species, number of samples attacked by drywood termites and pin-hole borers was much higher than that by powder-post beetles. Evaluation of the deteriorating grade of the wood samples having been mostly stored for more than 30 years caused by' the termites infestation showed that about 37 and $45 \%$, each represents 38 and 24 wood species, of the wood samples could be respectiveh categorized into very resistant and resistant. The rest, about 10,5 and $1 \%$, each of 15,6 and 2 species, were classified as moderate, not resistant and very not resistant. Among the highly resistant wood group, 27 species were uninfested at all.

Deteriorating grade caused by the pin-hole borers beetles was not recorded, but it seems to be not so important than that caused by the other pests. Even though powder-post beetles onty' infested a small number of the wood species, they caused heavy damage to their hosts.

\section{PENDAHULUAN}

Sejak didirikan sekitar tahun 1920, Pusat Penelitian dan Pengembangan Hasil Hutan dan Sosial Ekonomi Kehutanan Bogor, yang meskipun telah berganti nama beberapa kali, mempunyai misi utama yang tidak banyak berubah yaitu penelitian dan pengembangan hasil hutan agar kayu dan hasil hutan lainnya dapat dimanfaatkan sebaik-baiknya. Sejak waktu itu pula, lembaga ini secara terusmenerus mengumpulkan berbagai jenis kayu dari seluruh wilayah tanah air untuk berbagai keperluan penelitian. 
Tidak semua kayu habis terpakai untuk penelitian. Sebagian contoh kayu disimpan di xylarium sebagai xylotheca (koleksi), sedangkan yang lain, yang merupakan sisa bahan penelitian, disimpan di gudang dalam bentuk papan atau dalam bentuk sisa contoh uji yang sewaktu-waktu dapat dimanfaatkan sebagai cadangan bahan penelitian.

Kayu yang disimpan dalam waktu yang lama tentu saja tidak lepas dari ancaman organisme perusak. Terlebih lagi kota Bogor ini, dengan curah hujan dan kelembaban udaranya yang tinggi, sangat cocok untuk pertumbuhan dan perkembangan berbagai jenis hama perusak kayu. Jenis kayu tertentu yang mempunyai keawetan rendah mungkin akan rusak dalam waktu yang relatif singkat, namun jenis yang lain yang mempunyai keawetan tinggi mungkin akan tahan bertahun-tahun.

Serangga perusak kayu yang banyak ditemukan di Bogor dan sekitarnya adalah rayap dan bubuk. Rayap kayu kering Cryptotermes spp., sekelompok jenis rayap yang banyak ditemukan di berbagai wilayah di Indonesia yang menyerang kayu bangunan dan juga hasil olahannya misalnya kayu lapis, kertas dan lain-lainnya yang disimpan di bawah atap namun tidak berhubungan dengan tanah, merupakan salah satu ancaman terhadap keselamatan kayu koleksi atau kayu di gudang ini (Martawijaya et al., 1973).

Kerusakan kayu karena serangan bubuk, yang meliputi bubuk kayu kering dan bubuk kayu basah juga perlu diperhatikan. Bubuk kayu kering mempunyai habitat yang mirip rayap kayu kering yaitu menyerang kayu gergajian yang telah kering dan juga hasil olahannya. Bubuk kayu basah, yang disebut juga sebagai kumbang ambrosia, menyerang kayu yang telah ditebang, dolok dan kayu gergajian yang masih segar. Mungkin sekali serangan serangga penggerek ini pun akan berlanjut sampai beberapa waktu setelah kayu disimpan di gudang selama kayu masih cukup segar.

Karena kemungkinan kerusakan itu, kayu yang disimpan di gudang ini dapat dimanfaatkan sebagai uji daya tahan alami terhadap jenis hama perusak tersebut. Sebagian dari contoh kayu ini pernah diamati (Martawijaya et al., 1973) namun terbatas pada contoh uji yang telah tersimpan 10 tahun dan juga hanya kerusakan terhadap serangan rayap kayu kering. Suatu pengamatan dilakukan untuk mengetahui ketahanan alami berbagai jenis kayu yang disimpan di gudang terhadap serangan ketiga kelompok serangga perusak tersebut.

\section{BAHAN DAN METODE}

Contoh uji yang digunakan sebanyak 85 jenis (Lampiran 1) adalah kayu patok, sisa kayu untuk percobaan kuburan (grave yard) berukuran $5 \times 5 \times 60 \mathrm{~cm}$ (tebal x lebar $\mathrm{x}$ panjang) yang telah tersimpan di gudang sekurang-kurangnya 8 tahun. Sisa contoh uji ini ditumpuk di atas beberapa rak kayu agar tidak berhubungan langsung dengan lantai. Pada mulanya tempat yang digunakan sebagai penyimpanan berupa sebuah ruangan yang cukup terang namun sejak sekitar 10 tahun terakhir contoh kayu tersebut dipindałıan ke ruangan lain yang agak gelap. Tidak ada perlakuan tertentu dalam penyimpanan ini.

Pengamatan kerusakan kayu karena serangan rayap kayu kering dilakukan berdasarkan adanya luka bekas gigitan serangan serangga tersebut baik yang terlihat pada permukaan kayu maupun yang terdapat pada bagian dalamnya. Untuk 
mengamati serangan rayap yang terjadi di dalamnya, kayu contoh uji dibelah menjadi dua bagian.

Serangan rayap dinilai berdasarkan peringkat kerusakan kayu dengan kisaran nilai antara 0 (hancur) hingga 10 (utuh) (ASTM, 1991a, 1991b) sebagai tercantum pada Tabel 1.

Tabel 1. Derajat kerusakan kayu

Table 1. Deteriorating grade of wood

\begin{tabular}{cl}
\hline Nilai (Value) & Derajat kerusakan (Deteriorating grade) \\
\hline 10 & utuh (sound) \\
9 & serangan ringan (light) \\
7 & kerusakan sedang (moderate) \\
4 & serangan berat (heavy) \\
0 & hancur (failure) \\
\hline
\end{tabular}

Dari angka kerusakan ini, disusun klasifikasi daya tahan kayu berdasarkan nilai tengah antara dua peringkat nilai yang berurutan (Tabel 2).

Tabel 2. Daya tahan kayu

Table 2. Resistant grade of wood

\begin{tabular}{clc}
\hline Kelas (Class) & Daya tahan (Resistant grade) & Nilai selang (Intervale value) \\
\hline I & sangat tahan (very resistant) & $9.5-10$ \\
II & tahan (resistant) & $8.0-9.4$ \\
III & sedang (moderate) & $5.5-7.9$ \\
IV & tidak tahan (not resistant) & $2.0-5.4$ \\
V & sangat tidak tahan (very not resistant) & $<$ \\
\hline
\end{tabular}

Penilaian serangan bubuk kayu basah dan bubuk kayu kering dilakukan berdasarkan ada dan tidaknya lubang gerek (saluran) pada contoh kayu yang diamati dengan ciri sebagai berikut : serangan bubuk kayu basah berupa lubang gerek yang berwarna hitam mirip luka bekas tusukan kawat yang dibakar. Ukuran lubang gerek berbeda-beda tergantung pada jenis bubuk (ukuran tubuh bubuk) yang menyerangnya.Lubang gerek bersih, tidak ada serbuk gerek yang tertinggal di dalamnya. Kerusakan karena serangan penggerek ini terlihat dari permukaan contoh uji.

Sebaliknya, lubang gerek yang dibuat oleh bubuk kayu kering tidak mengalami pewarnaan dan lubang gereknya selalu terisi serbuk gerek bekas gigitan kayu atau kotoran lainnya. Ukuran lubang gerek beragam, selain tergantung pada jenis bubuk yang menyerangnya juga pada tingkat pertumbuhan larvanya. Untuk keperluan pengamatan, contoh uji perlu dibelah seperti halnya pada pengamatan serangan rayap kayu kering karena kegiatan penggerekan oleh bubuk kayu kering pun berlangsung di balik permukaan (di dalam) kayu.

\section{HASIL DAN PEMBAHASAN}

Pengamatan menunjukkan bahwa dari 464 potong contoh uji yang berasal dari 84 jenis kayu, tanpa membedakan tingkat kerusakannya, jumlah contoh uji yang mengalami kerusakan karena serangan rayap kayu kering, bubuk kayu kering dan 
bubuk kayu basah masing-masing adalah 198, 28 dan 210 buah (Tabel 3). Jadi sebagian terbesar contoh uji ditemukan masih utuh. Jumlah contoh uji yang diserang rayap kayu kering dan bubuk kayu basah menempati peringkat paling tinggi, jauh di atas yang diserang bubuk kayu kering.

Tabel 3. Rekapitulasi jumlah kayu contoh uji yang diserang rayap kayu kering, bubuk kayu kering dan bubuk kayu basah dari 464 contoh yang diamati.

Table 3. Recapitulation of number of wood samples infested by dry-wood termites, powder-post beetles and pin-hole berers of 464 observed samples.

\begin{tabular}{|c|c|c|c|c|c|}
\hline \multicolumn{2}{|c|}{$\begin{array}{c}\text { Serangan rayap kayu kering } \\
\text { (Infestation by dry-wood termites) }\end{array}$} & \multicolumn{2}{|c|}{$\begin{array}{c}\text { Serangan bubuk kayu kering } \\
\text { (Infestation by powder-post beetles) }\end{array}$} & \multicolumn{2}{|c|}{$\begin{array}{l}\text { Serangan bubuk kayu basah } \\
\text { (Infestation by pin-hole borers) }\end{array}$} \\
\hline $\begin{array}{l}\text { diserang } \\
\text { (infested) }\end{array}$ & $\begin{array}{l}\text { tak diserang } \\
\text { (uninfested) }\end{array}$ & $\begin{array}{l}\text { diserang } \\
\text { (infested) }\end{array}$ & $\begin{array}{l}\text { tak diserang } \\
\text { (uninfested) }\end{array}$ & $\begin{array}{l}\text { diserang } \\
\text { (infested) }\end{array}$ & $\begin{array}{l}\text { tak diserang } \\
\text { (uninfested) }\end{array}$ \\
\hline \multicolumn{6}{|c|}{ Jumlah contoh uji (Number of wood samples) } \\
\hline 198 & 266 & 28 & 436 & 201 & 263 \\
\hline
\end{tabular}

Rayap kayu kering, seperti halnya jenis rayap yang lain, kiranya tidak terlalu selektif dalam memilih sasaran serangan. Bubuk kayu basah pun demikian. Bahkan Browne (1952) pernah menyatakan bahwa tidak ada satu jenis kayu pun yang benar-benar tahan terhadap serangan kelompok serangga penggerek ini. Habitat bubuk kayu kering memang lebih terbatas pada jenis kayu yang mempunyai kandungan zat pati yang cukup tinggi. Itulah kiranya yang menyebabkan baik jumlah maupun contoh kayu yang diserang serangga hama ini jauh lebih sedikit daripada yang lain.

Tabel 4. Jumlah contoh uji, masa simpan dan peringkat kerusakan karena serangan rayap kayu kering.

Table 4. Number of samples, keeping duration and degree of deterioration caused by dry-wood termites.

\begin{tabular}{|c|c|c|c|c|c|}
\hline \multirow{2}{*}{$\begin{array}{l}\text { Derajat serangan } \\
\text { (Infestation grade) }\end{array}$} & \multirow{2}{*}{$\begin{array}{l}\text { Deskripsi kerusakan } \\
\text { (Deteriorating } \\
\text { descrpition) }\end{array}$} & \multirow{2}{*}{$\begin{array}{l}\text { Jumlah } \\
\text { jenis } \\
\text { (Number of } \\
\text { species) }\end{array}$} & \multicolumn{2}{|c|}{$\begin{array}{l}\text { Jumlah contoh uji } \\
\text { (Number of samples) }\end{array}$} & \multirow{2}{*}{$\begin{array}{c}\text { Masa simpan, tahun } \\
\text { (Storaging duraiion, year) } \\
\text { Rata-rata } \pm \text { simpangan baku } \\
(\text { Average } \pm S D)\end{array}$} \\
\hline & & & $\begin{array}{l}\text { Potong } \\
\text { (Pieces) }\end{array}$ & $\%$ & \\
\hline $9.5-10$ & $\begin{array}{l}\text { Sangat ringan - utuh } \\
\text { (Very light - sound })\end{array}$ & 38 & 177 & 38.15 & $37.17 \pm 9.73$ \\
\hline $8.0-9.4$ & Ringan (Light) & 24 & 209 & 45.04 & $37.61 \pm 7.90$ \\
\hline $5.5-7.9$ & Sedang (Moderate) & 15 & 49 & 10.56 & $34.08 \pm 12.32$ \\
\hline $2.0-5.4$ & Berat (Heavy) & 6 & 24 & 5.17 & $38.00 \pm 6.38$ \\
\hline$<\quad 2.0$ & Hancur (Failure) & 2 & 5 & 1.08 & $4.72 \pm 12.40$ \\
\hline Jumlah (Total) & & 84 & 464 & 100 & \\
\hline
\end{tabular}

Derajat kerusakan yang disebabkan oleh serangan bubuk kayu basah dan bubuk kayu kering tidak dicatat. Namun pengamatan dalam penelitian ini menunjukkan bahwa kerusakan yang disebabkan oleh serangan bubuk kayu basah tidak menim- 
bulkan kerusakan yang berarti dibanding yang disebabkan oleh rayap kayu kering. Jumlah contoh uji yang diserang bubuk kayu kering jauh lebih sedikit, hanya 28 contoh yang berasal dari 15 jenis kayu tetapi menimbulkan kerusakan yang hebat pada kayu yang diserangnya.

Berdasarkan rata-rata derajat kerusakan yang disebabkan oleh serangan rayap, sebanyak 177 potong contoh uji yang meliputi 37 jenis kayu masih utuh atau hanya mengalami kerusakan yang sangat ringan (Tabel 4 dan Lampiran 1). Dari jumlah tersebut, terdapat 27 jenis kayu yang meliputi 100 contoh uji yang benarbenar masih utuh (Lampiran 1). Peringkat di bawahnya adalah yang mengalami kerusakan ringan, yaitu sebanyak 209 potong contoh uji yang meliputi 24 jenis kayu. Hanya sebagian kecil saja yang mengalami kerusakan berat dan telah hancur.

Hasil penelitian ini, terutama dalam perbandingan jumlah contoh uji antara peringkat ketahanan yang satu dengan yang lain, banyak berbeda dari penelitian sebelumnya yang sebagian terbesar (lebih dari $60 \%$ ) tergolong sangat tahan sedangkan peringkat ketahanan di bawahnya masing-masing hanya sekitar $5 \%$ (Martawijaya et al., 1973). Perbedaan ini mungkin disebabkan oleh beberapa hal misalnya dalam hal umur simpan contoh uji, cara pengamatan dan juga jenis kayu. Contoh uji yang digunakan oleh Martawijaya et al. (1973) baru mencapai 10 tahun, dan cara pengamatannya juga tidak disebutkan, apakah berdasarkan pada serangan yang tampak pada bagian permukaan saja atau juga meliputi bagian dalamnya. Tanpa pembelahan contoh, kerusakan di dalam contoh uji belum tentu terlihat karena serangga perusak ini cenderung menyerang bagian dalam kayu, meninggalkan bagian permukaan yang tampak masih utuh. Jenis kayu yang diamati pun banyak yang berbeda.

Nisbah antara berbagai peringkat ketahanan yang dihasilkan dari penelitian ini pun berbeda dengan hasil penelitian laboratoris terhadap rayap kayu kering Cryptotermes cynocephalus yang dilakukan oleh Martawijaya dan Sumarni (1978) dengan metode uji paksa makan (force feeding test). Dalam penelitian mereka, rayap hanya dihadapkan pada jenis kayu tertentu yaitu contoh kayu yang diuji. Dalam keadaan seperti ini mungkin saja, karena kelaparan, rayap tersebut akan mencoba menyerang semua jenis kayu yang disediakan sehingga hampir pada semua contoh uji terdapat luka bekas gigitannya. Sebaliknya rayap yang banyak ditemukan di gudang secara alami dapat memilih jenis-jenis kayu yang disukainya, seperti halnya mereka menghadapi kayu bangunan di perumahan yang pada umumnya terdiri dari berbagai jenis kayu. Karena perbedaan itu, peringkat ketahanan suatu jenis kayu mungkin dapat berbeda antara penelitian yang satu dengan yang lain.

Umur simpan contoh uji rata-rata telah mencapai lebih dari 30 tahun. Bila tidak diganggu, mungkin jenis-jenis kayu tersebut, terutama yang tergolong dalam kelas tahan dan sangat tahan, akan mampu bertahan lebih lama lagi. Jadi sebagian besar jenis kayu yang diteliti dapat dikatakan mempunyai ketahanan alamiah yang cukup tinggi terhadap serangan rayap kayu kering. Kurun waktu selama 30 tahun kiranya sudah cukup lama bila dibandingkan dengan keperluan kayu untuk bangunan dalam kehidupan sehari-hari. Bahkan, terutama untuk masyarakat menengah ke atas, banyak bangunan yang masih termasuk baru sudah dibongkar untuk kemudian diubah karena alasan ketinggalan jaman. 
Permasalahan penting yang dihadapi dalam penelitian ini adalah jumlah contoh uji tiap jenis kayu yang kadang-kadang tidak memadai. Namun demikian, dengan menggunakan contoh uji yang sudah tersimpan cukup lama ini, hasil penelitian ini tentunya dapat digunakan sebagai sumber informasi bagi para pengguna.

\section{KESIMPULAN DAN SARAN}

Pembahasan ini sampai pada kesimpulan bahwa sebagian terbesar dari contoh kayu yang tersimpan dalam gudang lembaga penelitian ini dapat digolongkan ke dalam kelas antara sangat tahan dan tahan terhadap serangan rayap kayu kering dan hanya sekitar $20 \%$ yang menduduki peringkat di bawahnya, yaitu antara kurang tahan dan sangat tidak tahan. Sebagian terbesar dari kelompok yang sangat tahan ditemukan masih utuh, tidak ada tanda-tanda serangan rayap sama sekali.

Dari segi jumlah, contoh uji yang diserang bubuk kayu basah tidak banyak berbeda dari serangan rayap namun serangan hama penggerek ini tidak menimbulkan kerusakan yang berarti bila dibandingkan dengan serangan oleh kelompok hama perusak yang lain.

Hanya sebagian terkecil dari contoh uji (jenis kayu) yang diserang oleh bubuk kayu kering namun hama perusak ini dapat menimbulkan kerusakan yang berat
pada inangnya.

Jumlah contoh uji semacam ini di gudang sangat banyak. Oleh karenanya, adalah merupakan tantangan yang menarik untuk melanjutkan penelitian semacam ini karena informasi yang dihasilkan akan sangat bermanfaat bagi masyarakat luas.

\section{DAFTAR PUSTAKA}

American Society for Testing and Materials (ASTM). 1991a. Standard method of evaluating wood preservatives by field test stakes. D 1758-86. Annual Book of ASTM Standars, vol. 04.09 (Wood).

American Society for Testing and Materials (ASTM).1991b. Standard method for field evaluation of wood preservatives in round post-size speciemens. D 2278-66 (Reapproved 1986). Annual Book of ASTM Standards, Vol. 04.09 (Wood).

Browne, F.G.1952. Suggestions for future research in the control of ambrosia beetles. Malay. Forester. 15: 197-206.

Martawijaya, A., K. Kadir, and I. Kartasujana. 1973. Notes on the resistance of several wood species against dry-wood termites Cryptotermes spec. Research Note No.1, Forest Products Reseach Institute, Bogor.

Martawijaya, A. and G. Sumarni. 1978. Resistance of number of Indonesian wood species against Cryptotermes cynocephalus Light. Report No. 129, Forest Products Research Institute, Bogor.

Oey Djoen Seng. 1964. Berat Jenis dari Jenis-jenis Kayu Indonesia dan Pengertian Beratnya Kayu untuk Keperluan Praktek. Pengumuman No. 13 Lembaga Penelitian Hasil Hutan. Bogor. 


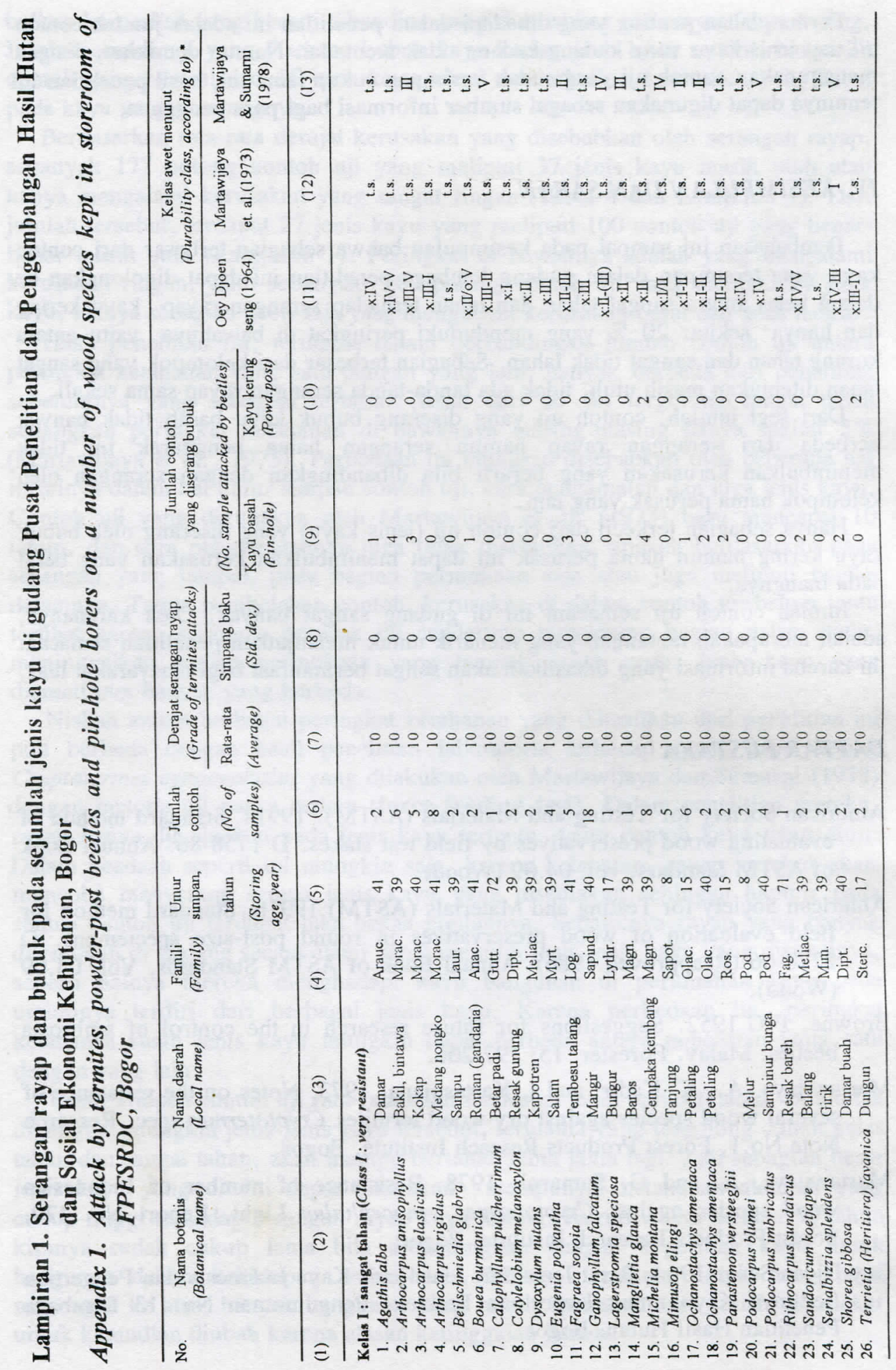




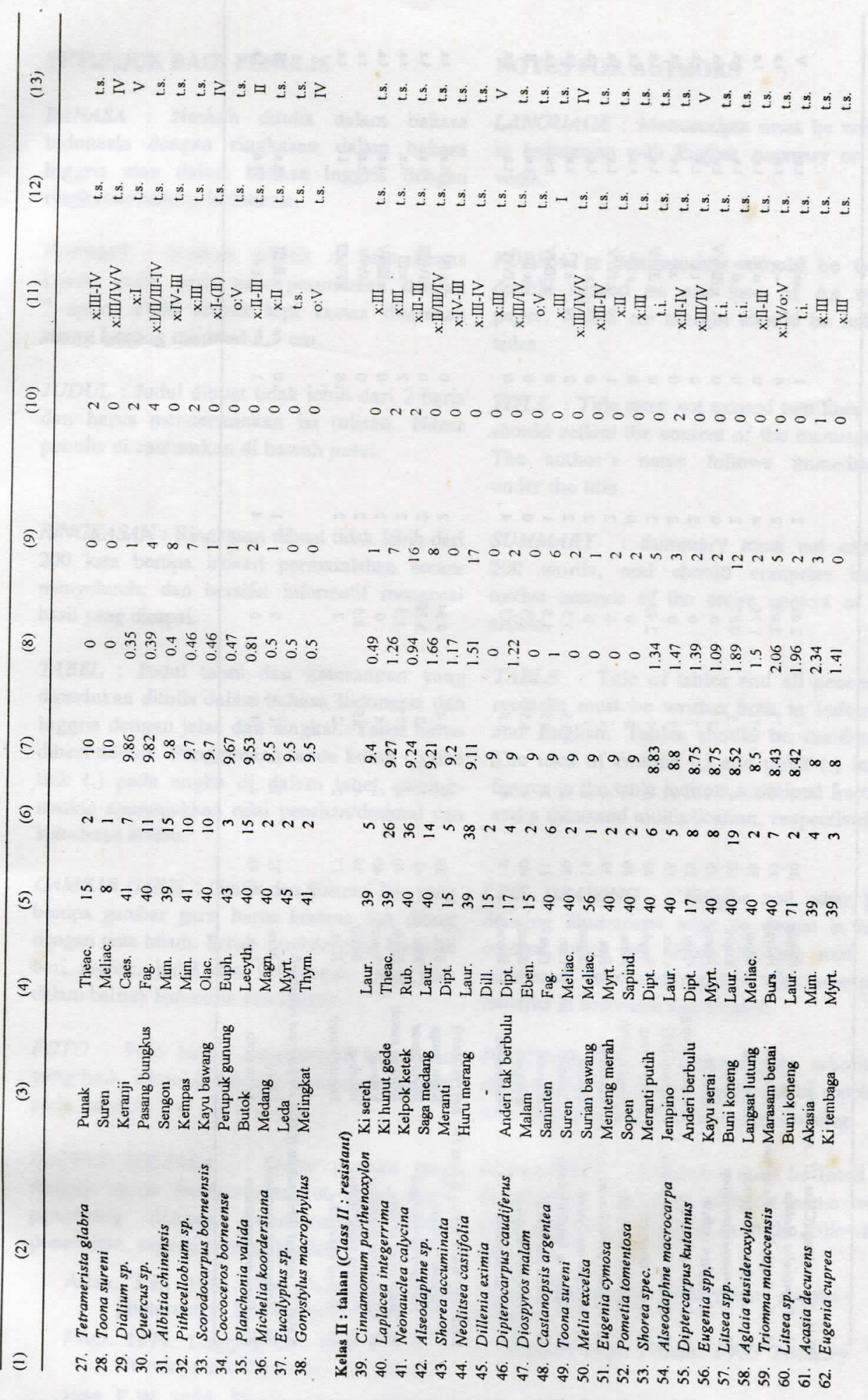

For. Prod. Res. J. Vol. 13 No. 3 (1995) 


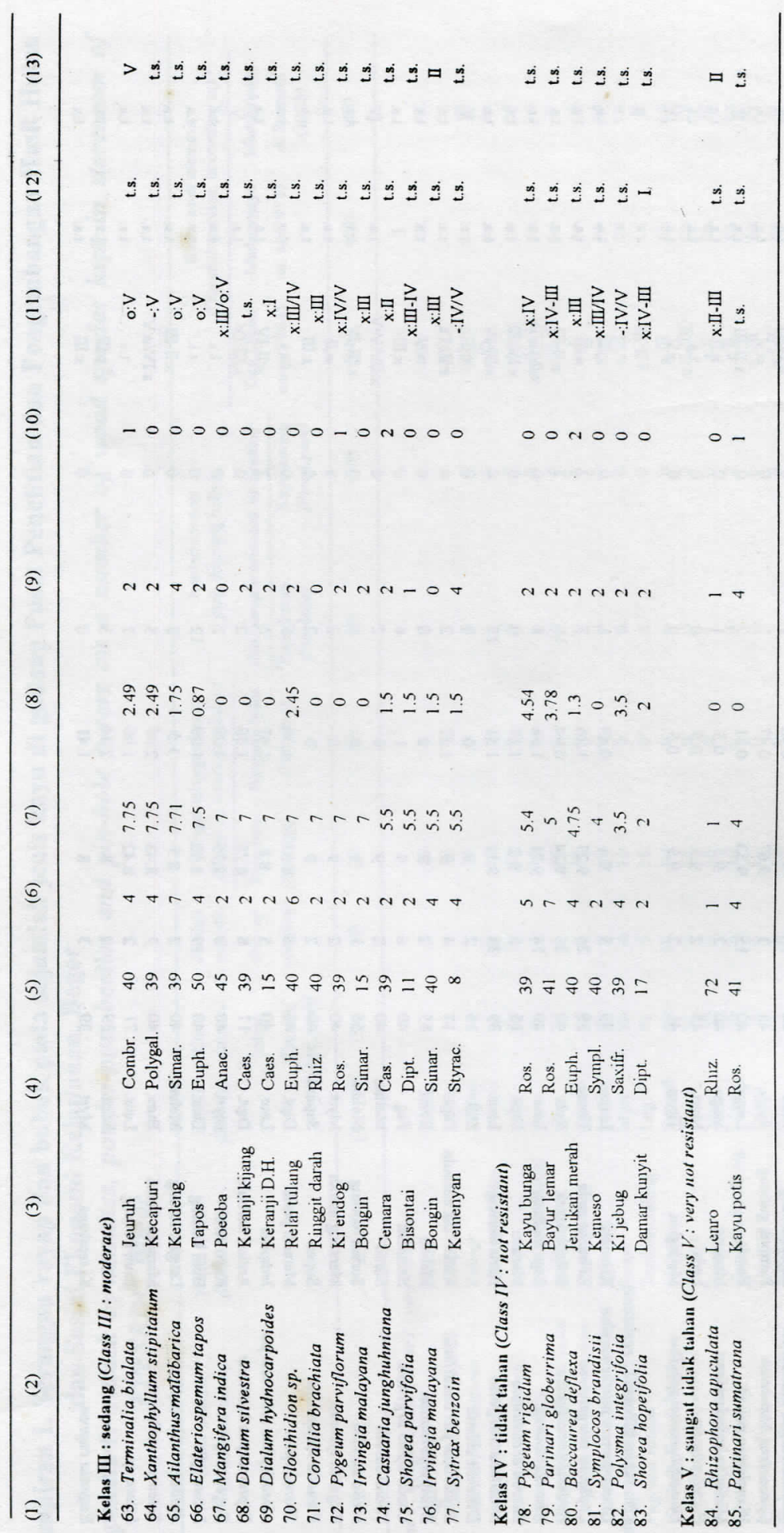




\section{PETUNJUK BAGI PENULIS}

BAHASA : Naskah ditulis dalam bahasa Indonesia dengan ringkasan dalam bahasa Ir.ggris atau dalam bahasa Inggris dengan ringkasan bahasa Indonesia.

FORMAT : Naskah diketik di atas kertas kuarto putih pada satu permukaan dengan 2 spasi. Pada semua tepi kertas disisakan ruang kosong minimal $3,5 \mathrm{~cm}$.

JUDUL : Judul dibuàt tidak lebih dari 2 baris dan harus mencerminkan isi tulisan. Nama penulis di cantumkan di bawah judul.

RINGKASAN : Ringkasan dibuàt tidak lebih dari 200 kata beripa intisari permasalahan secara menyeluruh, dan bersifat informatif mengenai hasil yang dicapai.

TABEL : Judul tabel dan keterangan yang diperlukan ditulis dalam bahasa Indonesia dan Inggris dengan jelas dan singkat. Tabel harus diberi nomor. Penggunaan tanda koma (,) dan titik (.) pada angka di dalam tabel masingmasing menunjukkan nilai pecahan/desimal dan kebulatan seribu.

GAMBAR GARIS : Grafik dan ilustrasi lain yang berupa gambar garis harus kontras dan dibuat dengan tinta hitam. Setiap gambar garis harus di beri nomor, judul dan keterangan yang jelas dalam bahasa Indonesia dan Inggris.

FOTO : Foto harus mempunyai ketajaman yang baik, diberi judul dan keterangan seperti pada gambar.

DAFTAR PUSTAKA : Daftar pustaka yang dirujuk harus disusun menurut abjad nama pengarang dengan mencantumkan tahun penerbitan, seperti teladan berikut :

\section{NOTES FOR AUTHORS}

LANGUAGE : Manuscripts must be written in Indonesian with English summary or vice versa.

FORMAT : Manuscripts should be typed double spaced on one face of $\mathrm{A}_{4}$ white paper. A $3,5 \mathrm{~cm}$ margin should be left all sides.

TITLE : Title must not exceed two lines and should reflect the content of the manuscript. The author's name follows immediately under the title.

SUMMARY : Summary must not exceed 200 words, and should comprise informative essence of the entire content of the article.

TABLE : Title of tables and all necessary remarks must be written both in Indonesia and English. Tables should be numbered. The uses of comms (,) and point (.) in all figures in the table indicate a decimal fraction, and a thousand multiplication, respectively.

LINE DRAWING : Graphs and other line drawing illustrations must be drawn in high contrast black ink. Each drawing must be numbered, titled and supplied with necessary remarks in Indonesia and English.

PHOTOGRAPH : Photographs submitted should have high contras, and must be supplied with necessary information as line drawing.

REFERENCE : Reference must be listed in alphabetical order of author's name with their year of publications as in the following example :

Allan, J.E. 1961. The determination of copper by atomic absorption spectrophotometry. Spectrochim. Acta , 17, 459-466.

FAO. 1974. Logging and Log Transport in Tropical High Forest. FAO Forestry Development Paper No. 18, Rome.

Jane, F.W. 1955. The Structure of Wood. Ist ed p. 328. London : Black. 
